\title{
Durability of different types of Mouthwashes on the Salivary Buffering system in Orthodontic Patients
}

\author{
Israa R. Alkasso', Sarmad S. Salih Al Qassar², Ghada A. Taqa' \\ ${ }^{1}$ Basic Science Department, College of Dentistry, University of Mosul, Mosul, Iraq \\ ${ }^{2}$ Orthodontics and Preventive Dentistry Department, College of Dentistry, University of Mosul, Mosul, Iraq
}

\section{Abstract}

The fast elevation of the salivary $\mathrm{pH}$ in orthodontic patients has acritical role to safe the teeth and encourage the orthodontic treatment after acidic challenger. As their baseline salivary $\mathrm{pH}$ is dropped during fixed orthodontic treatments.

Aims: This study was aimed to evaluate the durability of three types of mouthwashes on the salivary buffering capacity in orthodontic patients at $0,5,10,15$ mints after acidic challenger using direct pH meter.

Material and Method: 80 orthodontic patients; age range (13-21years) were distributed into four groups; 20/ each, the salivary $\mathrm{pH}$ were recorded using compact $\mathrm{pH}$ meter (LAQUAtwin, HORIBA's, Kyoto, Japan) before and after administration of carbonated beverage (100 $\mathrm{mm}$ coca cola) and directly after gargling with $5 \mathrm{ml}$ of the tested mouthwashes (herbal, green tea and chlorohexidine mouthwash) beside tap water as placebo control. The $\mathrm{pH}$ was documented again at 0, 5, 10 and 15 mins after each mouthwash gargling. One way ANOVA analysis and Duncan multiple were used for salivary $\mathrm{pH}$ analysis, $\mathrm{p} \leq 0.05$.

Results: non-significant differences were found at 0, 5, 10, 15 mints in comparison with baseline $\mathrm{pH}$ after herbal mouthwash gargling, the same result was shown with chlorohexidine mouth wash but with less defined border. Salivary $\mathrm{pH}$ after green tea gargling showed clear oscillatory results after the same tested periods.
Conclusion: Herbal mouthwash is the best type to improve salivary $\mathrm{pH}$ for longer duration after acidic challenger. While Chlorohexidine mouthwash shows beneficial effects in elevation salivary $\mathrm{pH}$ with less duration. Green tea mouthwash fail to control salivary $\mathrm{pH}$ for long duration.

Keywords: Salivary pH; orthodontic appliance; Herbal mouthwash; Green tea mouthwash; Chlorhexidine mouthwash.

Citation: Alkasso I, et al. (2021) Durability of different types of Mouthwashes on the Salivary Buffering system in Orthodontic Patients. Dentistry 3000. 1:a001 doi:10.5195/d3000.2021.161

Received: March 12, 2021

Accepted: April 14, 2021

Published: September 16, 2021

Copyright: (C2021 Alkasso l, et al. This is an open access article licensed under a Creative Commons Attribution Work 4.0 United States License. Email: sarmadsobhi@yahoo.com I sarmadsobhi@uomosul.edu.iq

\section{Introduction}

Dental Caries is the highest routine infectious disease worldwide. The interaction of shielding and deleterious factors in saliva and plaque considered as the elements that associate with caries incidence [1]. This incidence have a significant impact on patients wearing fixed orthodontic appliance, as the fixed appliance increase the occurrence of dental caries. Saliva is entirely unique oral fluid secreted from major and minor salivary glands. The usage of saliva in recognizing caries threat status for patients is well believed, which can be performed by evaluation the salivary flow rate, $\mathrm{pH}$ stage and lastly, its buffering capability. [1] Saliva $\mathrm{pH}$ ranges from (6.2 -7.6) with 6.7 practicality considered as the common $\mathrm{pH}$. Saliva $\mathrm{pH}$ of non caries teeth shouldn't fall below
6.3. Saliva, in turn, takes its role to control the $\mathrm{pH}$ of the oral cavity, which is maintained near neutrality (6.7 to 7.3 ). The saliva mechanism to preserve the $\mathrm{pH}$ consist of the draught of saliva eliminates carbohydrates that would be metabolized by the bacteria and removes acids that created by microorganism. Also, drinks and foods acidity alongside bacterial waste products, is canceled out by the saliva 
buffering action [2]. The ammonia release from urea metabolism by plague, this ammonia act to buffer the acidity of the saliva. However, the critical $\mathrm{pH}$ was reported to be 5.5 or less, in dental studies, thus any further drops in salivary $\mathrm{pH}$ would leads to teeth decay as a result of alteration of calcium and phosphate. As this $\mathrm{pH}$ is risky on progression of dental enamel [3]. Mouthwashes are antibacterial liquids held in the mouth temporarily and swished by the perioral muscles to eliminate the oral infections. As a liquid, these Mouthwashes reach all mouth areas that are hard to reach using dental brush. According to their content, mouthwashes are generally classified into cosmetic and therapeutic products [4]. Chlorhexidine is the golden option for treatment and controlling dental Plaque and gingival inflammations. It is well known act against Gram-positive and Gramnegative bacteria both aerobes and anaerobes, as well as yeasts, fungi and virus's lipid envelope [5, $6,7]$. Up to date, several synthetic mouthwashes are offered in the supermarkets. However, their side effects such as toxicity, hypersensitivity, and tooth staining limited it's used. The alternative option is medicines that are industrialized from medicinal Plants. These Plants are usually containing natural phyto- chemicals and henceforth, can replace synthetic medications [6]. Green tee also, has a multiple advantage for oral health. The previous studies focused on treatment aspects of mouthwashes regardless their effects on the saliva. The public queries that commonly arise is which one is well in improving saliva buffering capacity (chlorhexidine and herbal mouth). Hence, this study was designed to ask this question. Also, this study used to evaluate the effects of herbal, chlorohexidine as well as Green tea as mouthwash to test the durability of buffering capacity of the saliva over $0,5,10,15$ mints using direct $\mathrm{pH}$ meter.

\section{Material and Methods}

Study design

This study was designed as a double blinded randomized controlled trail. The protocol of this study was revised and accepted by research ethics committee of the Collage of Dentistry, University of Mosul (no. 26139 date 22\9\2019). According to the pilot study results, sample size was calculate utilizing $G$ power software as follow: power of study was $85 \%, \alpha=0.05$, constant proportion was 0.5 , the result was total sample size was 18 per group. We recruited 20 patients per group for more precise the results. Eighty orthodontic patients seeking dental treatments in dental hospital at the dental school/ university of Mosul were asked to participate in this study. Each patient signed special constant form, which was previously prepared for this purpose. The patients' age range was (13-21 years). The inclusion criteria include healthy orthodontic patients wearing fixed orthodontic appliance (Roth "22 stainless steel brackets, Ultratrim, Dentaurum, Ispringen, Germany) within the last two months that were neither complain from any systemic disease nor under daily drug course that could excreted in the saliva and hinder the results. The recruited patients were divided into four groups (20 for each) according to the type of the mouthwashes under investigation as follow: Herbal group (HG), Chlorohexidine group (CG), Green tea Group (FG) and tap water group (TG) which act as placebo negative. The patients and the observer were blinded to the type of the mouth wash used.

\section{Measurement procedure}

Each patient was instructed to stop eating and drinking at all for an hour before the morning appointment after well brushing of his teeth one night before. The patient set at morning in upright 
position in the dental chair and initial salivary $\mathrm{pH}$ was measure by spitting a sufficient amount directly on the dish part of the $\mathrm{pH}$ meter (HORIBA's LAQUAtwin, Horbia instruments incorporated, Kyoto, Japan). Then the subject was instructed to gargle with a $(100 \mathrm{ml})$ of Coca Cola ${ }^{\circledR}$

(Carbonated beverage) for 10 seconds before swelling it. Patient saliva $\mathrm{pH}$ was re-measured and recorded immediately after Coca Cola swallowing and 5, 10, 15 mints after respectively, using the same above procedures and device.

For HG, the above procedure was repeated one day after, as the patient was instructed to gargle with constant amount $(5 \mathrm{ml})$ of herbal mouthwash (Vitex maximum orthodontic care mouthwash (CJSC "Vitex" in Republic of Belarus) for 5 - $10 \mathrm{sec}$ [according to British National Formulary 77] before Coca Cola swallowing. The salivary $\mathrm{pH}$ was measured immediately after that and 5, 10, 15 mints subsequently. The same above procedure was repeated using the chlorohexidine mouth wash (Biofresh, Scitra Co. in United Arab Emirates), tap water and Green tea (Ahmad tea, London, United Kingdom) according to their group. Green tea mouth wash was prepared by dipping five tea bags in $100 \mathrm{ml}$ of boiling water, then let it cool at room temperature for about one hour before give it to patients. All the mouthwashes were packed in totally black bottles to a chive a double blind of the observer and participates.

The $\mathrm{pH}$ meter was cleaned and washed with plenty of distal water after each measurement and re calibrated using special wellknown $\mathrm{pH}$ liquids that was provided with it.

\section{Statistical analysis}

The data that had been collected throughout the study have been processed and analysed by using SPSS 23 (Statistical Package for the Social Sciences) (SPSS Inc., Chicago, USA). It was used to calculate mean and stander deviation for each salivary $\mathrm{pH}$ measurement for all groups. One way ANOVA analysis and Duncan multiple range test was used to find differences in salivary $\mathrm{pH}$ measurements for mouthwashes in compare with baseline salivary $\mathrm{pH}$ and to find differences in salivary $\mathrm{pH}$ measurement between all locally active tested products $(p \leq 0.05)$.

\section{Results}

Table 1. shows the mean age for all patients participated in this study classified according to type of mouth wash used, which was
(15.97 SD 4.01) years, with no significant difference between age groups, female represent (80\%) for whole patients that participate in our study compare with $(20 \%)$ for male with no significant difference between the two genders at $(p \leq 0.05) p$ value was 0.763 .

Salivary $\mathrm{pH}$ measurement after Herbal mouthwash gargling

Herbal mouthwash $\mathrm{pH}$ was (7.2). The results of measurement salivary $\mathrm{pH}$ for patients after herbal mouthwash were shown in Table 2, that shows the means and stander deviation of each salivary $\mathrm{pH}$ measurements, and the result of comparison of salivary $\mathrm{pH}$ for patients at different intervals from gargling with herbal mouthwash using One way analysis of variance (ANOVA) that reveal a significant difference in salivary $\mathrm{pH}$ after Coca cola in compare with Baseline, 0 , 5, 10 and 15 min salivary $\mathrm{pH}$ after gargling with herbal mouthwash $(p \leq 0.05)$, while there were no significant differences between the salivary $\mathrm{pH}$ at $0,5,10$ and 15 and baseline $\mathrm{pH}$ at $(\mathrm{p} \leq 0.05)$.

Salivary $\mathrm{pH}$ measurement after Chlorohexidine gargling

Chlorohexidine mouthwash $\mathrm{pH}$ was 6.3. The results of measurement salivary $\mathrm{pH}$ for patients after chlorohexidine mouthwash were shown in Table 3 that shows the means and stander 
deviation of each salivary $\mathrm{pH}$ measurement and the result of comparison for salivary $\mathrm{pH}$ measurement at different time from chlorohexidine gargling by One way analysis of variance (ANOVA) that reveal a significant difference in salivary $\mathrm{pH}$ after coca cola in compare with baseline 0 , 5,10 and $15 \mathrm{~min}$ salivary $\mathrm{pH}$ after gargling with chlorohexidine mouthwash ( $p \leq 0.05)$, there were also a significant differences between 0 min salivary $\mathrm{pH}$ after gargling with 15 min salivary $\mathrm{pH}$ measurement ( $p \leq 0.05)$, while there were no significant differences between salivary $\mathrm{pH}$ measurement at 5, 10 and baseline $\mathrm{pH}$ in compare with 0 and 15 min salivary $\mathrm{pH}$ measurement after chlorohexidine mouthwash.

Tap water mouthwash and salivary $\mathrm{pH}$ Measurements

Tap water $\mathrm{pH}$ was (7.4) the results of salivary $\mathrm{pH}$ measurement for patients after tap water mouthwash were shown in Table 4 at which we reveal the means and stander deviation of each salivary $\mathrm{pH}$ measurement and the result of comparison for these salivary $\mathrm{pH}$ measurement by One way analysis of variance (ANOVA) which reveal a significant difference in Coca Cola salivary $\mathrm{pH}$ in compare with Baseline, 0, 5, 10 and $15 \mathrm{~min}$ salivary $\mathrm{pH}$ after tap water mouthwash $(p \leq 0.05)$, There were also a significant difference in 15 min salivary $\mathrm{pH}$ from tap water mouthwash in compare with Baseline and 0 min salivary $\mathrm{pH}$ from tap water Mouthwash at ( $p \leq 0.05)$, While there were no significant differences between baseline $\mathrm{pH}$ in compare with 0,5 , and 10 min salivary $\mathrm{pH}$

measurement after tap water gargling at $(p \leq 0.05)$.

Green tea mouthwash and salivary $\mathrm{pH}$ measurements

The results of measurement salivary $\mathrm{pH}$ for patients after green tea mouthwash (mouthwash solution $\mathrm{pH}$ 5.7) were shown in Table 5 at which we reveal the means and stander deviation of each salivary $\mathrm{pH}$ measurement and the result of comparison for salivary $\mathrm{pH}$ measurement after green tea mouthwash by One way analysis of variance (ANOVA) that reveal a significant difference in baseline salivary $\mathrm{pH}$ in compare with coca cola salivary $\mathrm{pH} 0,5,10$ and 15 min salivary $\mathrm{pH}$ after gargling with green tea mouthwash ( $p \leq 0.05)$, There were a significant difference at $0 \mathrm{~min}$ salivary $\mathrm{pH}$ after green tea mouthwash in compare with coca cola salivary $\mathrm{pH} \mathrm{5,} 10$ and $15 \mathrm{~min}$ salivary $\mathrm{pH}$ after green tea mouthwash gargling $(p \leq 0.05)$ and there were a significant difference between coca cola salivary $\mathrm{pH}$ in compare with salivary $\mathrm{pH}$ after
15 min from green tea mouthwash $(p \leq 0.05)$, while there were no significant differences between Omin and baseline, coca cola in compare with 5 and $10 \mathrm{~min}$. also no significant differences between 15 min in compare with 0,5 and 15 min salivary $\mathrm{pH}$ measurement at $(p \leq 0.05)$.

Comparison between different mouthwashed used in this study

The results of comparison salivary $\mathrm{pH}$ measurement between orthodontic patients' groups after gargling with different mouthwash (Herbal, Chlorohexidine, Green tea and tap water) were shown in Table 6 at which we reveal the means and stander deviation of salivary $\mathrm{pH}$ measurement for each group. The result of comparison by One way analysis of variance (ANOVA) which reveal a significant difference between herbal group and green tea group at 0 min from gargling, a significant difference between green tea groups at 5 min with herbal, chlorohexidine and tap water groups at $5 \mathrm{~min}$, significant difference between green tea groups at 10 min with herbal, chlorohexidine and tap water groups at $10 \mathrm{~min}$, also a significant difference between tap water groups at $10 \mathrm{~min}$ with herbal and green tea groups and a significant difference between herbal at $15 \mathrm{~min}$ with tap water and green tea groups. 
Vol 9 No 1 (2021) DOI 10.5195/d3000.2021.161

Table 1. The mean age differences between the groups.

\begin{tabular}{|c|r|c|c|}
\hline Groups & Age & F & P-value \\
& (mean (years) \pm SD) & & \\
\hline Herbal Mouthwash HG & $(17.1 \pm 4.35)$ & & \\
\hline Chlorohexidine Mouthwash CG & $(15.3 \pm 3.20)$ & \multirow{2}{*}{0.025} & \\
\hline Tap water Mouthwash TG & $(15.7 \pm 2.53)$ & & \\
\hline Green tea Mouthwash FG & $(15.8 \pm 4.960)$ & & \\
\hline
\end{tabular}

$p \leq 0.05$.

Table 2. One way ANOVA for salivary pH after Herbal Mouthwash

\begin{tabular}{|c|c|c|c|}
\hline Groups & $\begin{array}{c}\mathrm{pH} \\
(\text { mean } \pm \mathrm{SD})\end{array}$ & $\mathbf{F}$ & P-value \\
\hline Baseline & $(6.65 \pm 0.303) a$ & \multirow{6}{*}{22.254} & \multirow{6}{*}{0.000} \\
\hline After Coca Cola & $(5.47 \pm 0.689) b$ & & \\
\hline 0 min from gargling & $(6.79 \pm 0.110) a$ & & \\
\hline 5 min from gargling & $(6.7 \pm 0.115) a$ & & \\
\hline $10 \mathrm{~min}$ from gargling & $(6.58 \pm 0.139) a$ & & \\
\hline $15 \mathrm{~min}$ from gargling & $(6.53 \pm 0.188) a$ & & \\
\hline
\end{tabular}

a: homogenous group, $b$ and $c$ : significant differences at $p \leq 0.05$. 
Table 3. One way ANOVA of salivary $\mathrm{pH}$ after chlorohexidine mouthwash

\begin{tabular}{|c|c|c|c|}
\hline Groups & $\begin{array}{c}\mathrm{pH} \\
(\text { mean } \pm \mathrm{SD})\end{array}$ & $F$ & P-value \\
\hline Baseline $\mathrm{pH}$ & $(6.54 \pm 0.195) a b$ & \multirow{6}{*}{18.494} & \multirow{6}{*}{0.000} \\
\hline After Coca Cola & $(5.65 \pm 0.636) b$ & & \\
\hline 0 min from gargling & $(6.73 \pm 0.231) a$ & & \\
\hline $5 \mathrm{~min}$ from gargling & $(6.59 \pm 0.159) a b$ & & \\
\hline $10 \mathrm{~min}$ from gargling & $(6.51 \pm 0.166) \mathrm{ab}$ & & \\
\hline $15 \mathrm{~min}$ from gargling & $(6.37 \pm 0.194) b$ & & \\
\hline
\end{tabular}

a: homogenous group, $b$ significant differences at $p \leq 0.05$.

Table 4. One way ANOVA of salivary $\mathrm{pH}$ after tap water mouthwash

\begin{tabular}{|c|c|c|c|}
\hline Groups & $\begin{array}{c}\mathrm{pH} \\
(\text { mean } \pm \mathrm{SD})\end{array}$ & $F$ & P-value \\
\hline Baseline $\mathrm{pH}$ & $(6.61 \pm 0.281) a$ & \multirow{6}{*}{23.184} & \multirow{6}{*}{0.000} \\
\hline After Coca Cola & $(5.54 \pm 0.532) b$ & & \\
\hline 0 min from gargling & $(6.62 \pm 0.155) a$ & & \\
\hline $5 \mathrm{~min}$ from gargling & $(6.49 \pm 0.129) a c$ & & \\
\hline $10 \mathrm{~min}$ from gargling & $(6.42 \pm 0.114) a c$ & & \\
\hline $15 \mathrm{~min}$ from gargling & $(6.31 \pm 0.099) c$ & & \\
\hline
\end{tabular}

a: homogenous group, $b$ and $c$ : significant differences at $p \leq 0.05$. 
Table 5. One way ANOVA of salivary $\mathrm{pH}$ after green tea mouthwash

\begin{tabular}{|c|c|c|c|}
\hline Groups & $\begin{array}{c}\mathrm{pH} \\
(\text { mean } \pm \mathrm{SD})\end{array}$ & $\mathbf{F}$ & P-value \\
\hline Baseline $\mathrm{pH}$ & $(6.69 \pm 0.202) a$ & \multirow{6}{*}{6.496} & \multirow{6}{*}{0.000} \\
\hline After Coca Cola & $(5.91 \pm 0.574) b$ & & \\
\hline 0 min from gargling & $(6.54 \pm 0.408) a c$ & & \\
\hline 5 min from gargling & $(6.02 \pm 0.426) b c$ & & \\
\hline $10 \mathrm{~min}$ from gargling & $(6.18 \pm 0.234) b c$ & & \\
\hline $15 \mathrm{~min}$ from gargling & $(6.32 \pm 0.244) c$ & & \\
\hline
\end{tabular}

a: homogenous group, $b$ and c: significant differences at $p \leq 0.05$.

There were no significant differences at $\mathrm{O}$ min salivary $\mathrm{pH}$ between all groups as they elevated salivary $\mathrm{pH}$ directly after gargling. Herbal mouthwash has the highest $\mathrm{pH}$ (7.2), chlorohexidine was in the second place by (6.73), Tap water at the third place by (6.62) and lastly home-made green tea mouthwash (6.54). After five minutes from gargling with mouthwashes there were a significant difference between green tea (6.02) in compare with Herbal (6.7), chlorohexidine (6.59) and tap water (6.49) that is also lesser than baseline salivary $\mathrm{pH}$, these mean mouths become more acidic after 5 minutes from green tea mouthwash. After 10 minutes from mouthwashes gargling there were a significant difference between green tea $\mathrm{pH}$ (6.18) with herbal (6.58), chlorohexidine (6.51) and tap water (6.42) mouthwashes, also there were significant differences between tap water (6.42) with herbal (6.58) and green tea (6.51) mouthwashes. After 15 minutes from gargling with mouthwashes there were a significant difference between green tea (6.31) salivary $\mathrm{pH}$ with herbal mouthwash (6.53) also, significant differences between tap water (6.32) mouthwashes with herbal mouthwash (6.53), while there were no significant differences between chlorohexidine (6.37) and other mouthwashes after 15 minutes from gargling.

The durability of each mouth washes used in this study after acid challenger are shown in Figure 1 for different intervals. 
Table 6. One way ANOVA of salivary $\mathrm{pH}$ after green tea mouthwash

\begin{tabular}{|c|c|c|c|c|}
\hline $\begin{array}{l}\frac{0}{\pi} \\
\frac{5}{\pi}\end{array}$ & 엄 & $\begin{array}{l}8 \\
0 \\
0\end{array}$ & O̊ㅁ & $\begin{array}{l}\tilde{m} \\
0 \\
0\end{array}$ \\
\hline 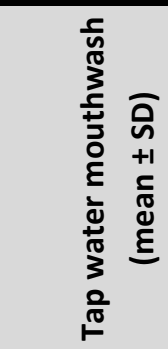 & 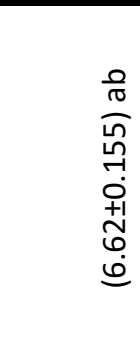 & 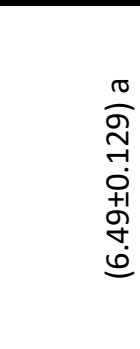 & 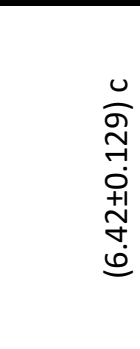 & 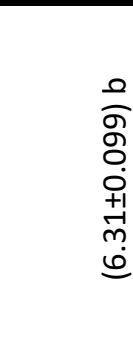 \\
\hline 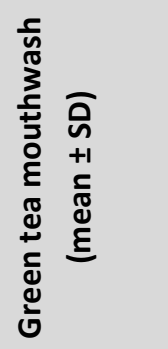 & $\begin{array}{l}0 \\
\text { o } \\
\text { o } \\
+ \\
0 \\
+1 \\
\text { +⿱ } \\
\text { ம. }\end{array}$ & 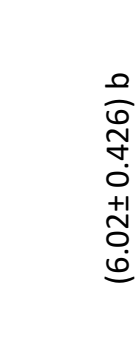 & $\begin{array}{l}0 \\
\stackrel{0}{f} \\
\stackrel{N}{N} \\
0 \\
+1 \\
\infty \\
\stackrel{1}{1} \\
\dot{\omega}\end{array}$ & 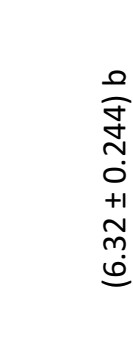 \\
\hline 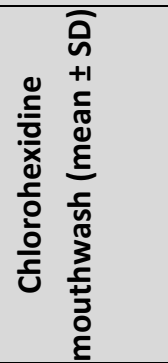 & $\begin{array}{l}\stackrel{0}{-} \\
\stackrel{n}{N} \\
0 \\
+1 \\
\stackrel{1}{N} \\
\dot{\theta}\end{array}$ & 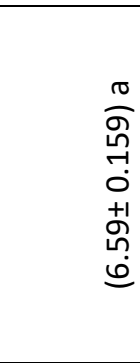 & 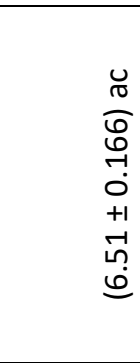 & $\begin{array}{l}\frac{0}{\sigma} \\
\stackrel{5}{\sigma} \\
\stackrel{+}{0} \\
+ \\
+1 \\
\hat{n} \\
\stackrel{0}{0}\end{array}$ \\
\hline 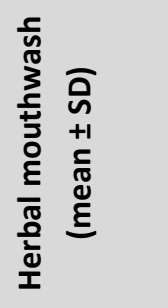 & 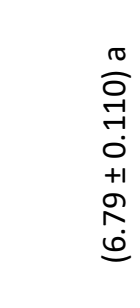 & 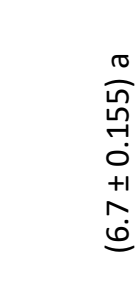 & $\begin{array}{l}\stackrel{\sigma}{a} \\
\stackrel{m}{1} \\
\stackrel{1}{0} \\
+1 \\
\infty \\
0 \\
\stackrel{0}{0}\end{array}$ & 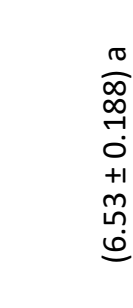 \\
\hline $\begin{array}{l}\text { ò } \\
\text { 인 }\end{array}$ & $\begin{array}{l}\stackrel{\complement}{\varepsilon} \\
\circ\end{array}$ & 妾 & $\begin{array}{l}\stackrel{\subsetneq}{\xi} \\
\stackrel{\overbrace{}}{\circ}\end{array}$ & $\begin{array}{l}\stackrel{\complement}{\bar{\varepsilon}} \\
\stackrel{n}{\sim}\end{array}$ \\
\hline
\end{tabular}

a: homogenous group, b and c: significant differences at $p \leq 0.05$. 


\section{Discussion}

Saliva acidity consider as critical factor in dental erosion, which defined as the chemical process that lead to loss of tooth hard tissue without cooperation of bacteria, dental erosion incidence has been expanded in current years and it is presently taken into consideration to be a worldwide oral sickness, for that salivary acidity is the important threshold for this chemical process that cause dental tissue dissolution [7].

In orthodontic patients, the control of the $\mathrm{pH}$ of the saliva has a primary importance, as it was reported that the $\mathrm{pH}$ of saliva in orthodontic patients dropped significantly after only one month from starting the fixed orthodontic therapy [8]. Additionally, Toodehzaeim and Khanpayeh, [8], clarified that acidic saliva has an adverse effect on brackets bonding, and archwire surface roughness that could be delay orthodontic treatment. The Checking out of the erosive capability on human teeth makes feel with substances having $\mathrm{pH}$ values under 5.5. Saliva had the ability to compensate these dropping in $\mathrm{pH}$ by its dynamic system withen $15-60$ min, but this not consider a fast process as

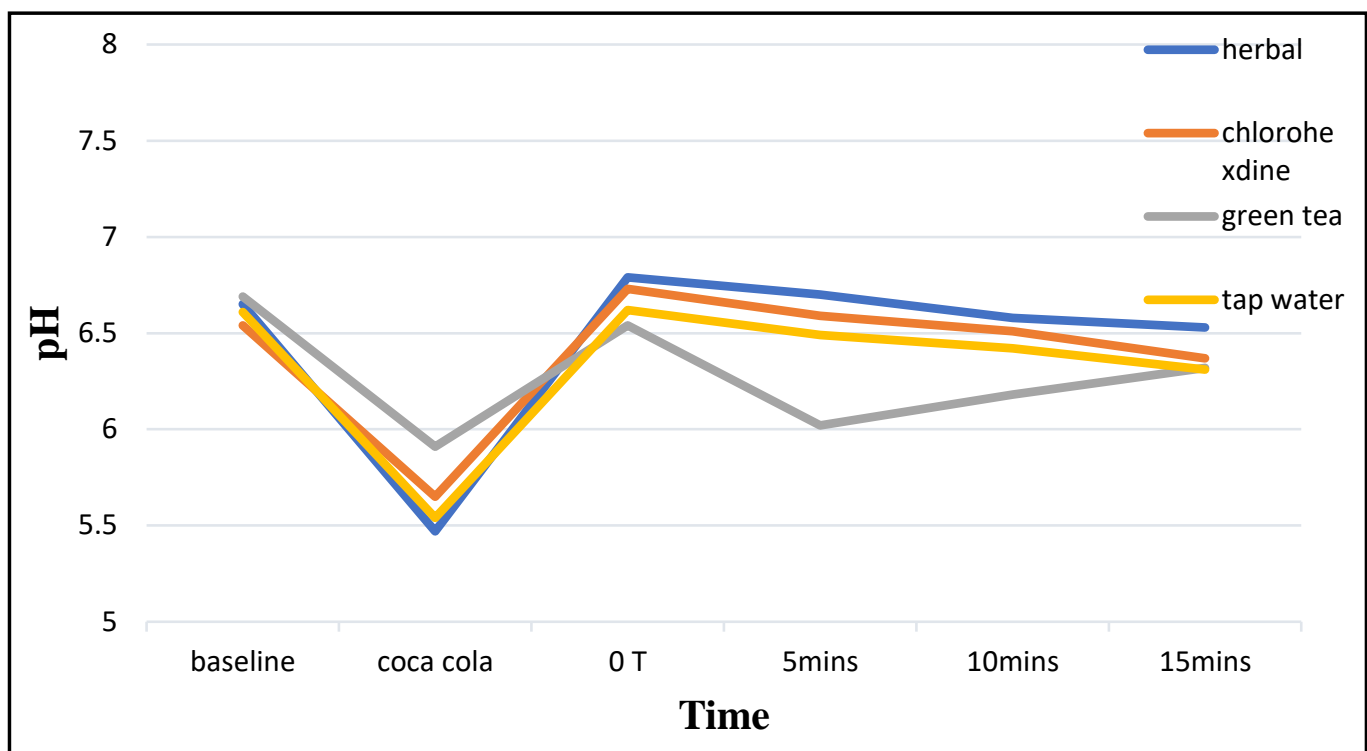

Figure 1 Durability of Salivary pH for different mouthwashes used in this study.

dental erosion progression start only after $5 \mathrm{~min}$ from exposure to acidic challenger [9].

In this study, a new $\mathrm{pH}$ meter was used to measure the $\mathrm{pH}$ of the saliva of the volunteers, which is more realable and accurate than $\mathrm{pH}$ strip, as these strips has no exact clear measurements of the salivary $\mathrm{pH}$.

Three types of mouthwashes were evaluated in this study which are the most popular used, Tap water also was used as placebo control, which is most accessible one. Different intervals were selected $(0,5,10,15$ mints) to find out the faster mouthwash that could elevated the salivary $\mathrm{pH}$ for longer duration.

\section{Coca Cola and salivary $\mathrm{pH}$}

Our results showed that the consumption of the Coca Cola dropping the $\mathrm{pH}$ of the saliva to reach the critical $\mathrm{pH}$ which was reported to be the main causative factor of teeth demineralization and subsequent teeth decays [2]. This could be due to the high percentage of carbonate induced in the Coca Cola. This fallen $\mathrm{pH}$ was re-elevated gradually with time to reach $83 \%$ from baseline $\mathrm{pH}$ after only 5 mints, and to reach 88.95\% after 15 mints of beverage intake. However, there are a significant difference between these time intervals. Normally the saliva has an ability to control and balance the acidic challenger within $15-60$ mints $[2,10,11]$.

\section{Herbal mouthwash}

As herbal mouthwash has alkaline $\mathrm{pH}$ (7.2), saliva $\mathrm{pH}$ up surged directly to higher $\mathrm{pH}$ than baseline $\mathrm{pH}$ after gargling with it, that persist for $5 \mathrm{~min}$ then it retains to 
approach baseline $\mathrm{pH}$ and dropped after 10, 15 mints respectively with good durability, with no significant between these intervals and base line $\mathrm{pH}$. Herbal mouth washes has a refreshing feeling with no bitter test or loss of sensation which seen with other chemical mouthwash, with less staining and pleasant taste induced in the synthetic mouthwashes and also, they're better in cost $[6,12]$. Recently, the trend to used natural products become more popular as they have high antimicrobial efficiency, safe and reasonably-priced as well. Triclosan content of the herbal mouthwashes has an ability to increase the salivary $\mathrm{pH}$ immediately $[6,12]$.

Sandhya, in 2017 [13] reported that the traditional mouthwash comprises of the high alcoholic content which can cause harm to the teeth, gums and the oral mucosa. While the natural mouthwash doesn't contain any alcoholic residue and is gentler on the mouth. Beside all of above, the use of herbal mouthwash enhances the saliva buffering capacity immediately. One of its limitation is that it's difficult to be taking every time as it is bulk to be transported or taking everywhere.

Chlorohexidine mouthwash
Our result showed that taken chlorohexidine mouthwash, which have alkaline $\mathrm{pH}$, directly after carbonated beverage elevated salivary $\mathrm{pH}$ directly higher than baseline $\mathrm{pH}$, that persist for 10 min insignificantly, then drop back to have $\mathrm{pH}$ lower than baseline $\mathrm{pH}$ after 15 mins from chlorohexidine mouthwash however with no significant difference between them. Thus, the immediate one time used of chlorohexidine mouthwash has a significant, but a short-lasting effect on salivary $\mathrm{pH}$.

This conclusion is agree with Kalyani \& Leelavathi [14] as they found that chlorohexidine mouthwash have a positive effect on the salivary $\mathrm{pH}$, which is also prolonged in nature. On the other hand, this study is in disagreement with Bescos et al., [15] how found that salivary $\mathrm{pH}$ and salivary buffering capacity are highly diminished after using chlorohexidine mouthwash, however, their study conducted twice daily for one week, as chlorohexidine use is associated with high increase in saliva lactate, glucose and nitrate concentration.

\section{Green tea mouthwash}

As saliva $\mathrm{pH}$ drop immediately after drinking carbonated beverage green tea mouthwash succeed to increase $\mathrm{pH}$ directly to reach $\mathrm{pH}$ higher than critical salivary acidic $\mathrm{pH}$ but lower than baseline $\mathrm{pH}$, then it dropped again to almost reach $\mathrm{pH}$ after carbonated beverage (after 5 mints), then retain to elevation after 15 mins from green tea mouthwash. The green tea mouthwash has a significant, but a short-lasting effect on salivary $\mathrm{pH}$ (less durability).

Talreja et al., [16] and Lee et al., [17] uncovered that the catechins (green tea extract) were held for $60 \mathrm{~min}$ in saliva and protected plaque $\mathrm{pH}$ toward neutrality and also it have antiplaque and antibacterial properties by collaboration with boundary work of microorganism and consumption of this bunch, in this way contributing to caries prevention.

This results agreed with Singh, [18] Kamalaksharappa et al., [19] Srinidhi et al., [20] Rathod, [21] and Sangameshwar, [22] there were a significant increase in salivary $\mathrm{pH}$ after rinsing with green tea mouthwash. However, our results shows short improvements effects.

\section{Tap water mouthwash}

Tap water mouthwash (pH 6.8), after carbonated beverage, rise the salivary $\mathrm{pH}$ directly to reach to $\mathrm{pH}$ higher than baseline $\mathrm{pH}$, that persist for few minutes then drop 
back to have $\mathrm{pH}$ lower than baseline $\mathrm{pH}$ after $15 \mathrm{mins}$, but higher than $\mathrm{pH}$ after carbonated beverage. Here we demonstrate that tap water mouthwash has a significant, but a short-lasting effect of salivary $\mathrm{pH}$. This type of mouthwash considers the simplest and most accessible type of mouthwashes, with safe and cheap considerations with insignificant durability from baseline $\mathrm{pH}$ after 10 mint.

We agreed with Kalyani and Leelavathi, [14], as they claimed that quick increment within salivary $\mathrm{pH}$ after $5 \mathrm{~min}$. from water gargling. Also, we agree with Mosallam \& Mohamed, [24, 23] who found that water gargling after dropping in salivary $\mathrm{pH}$ leads to neutralization of salivary $\mathrm{pH}$, thus could be consider as a simple preventive measure of caries process in young adults.

In 2014 Lim [23] discover that water mouth rinsing after suppers plays a basic part in maintaining mouth health. As already depicted, water with $\mathrm{pH}$ at 7.0 demonstrates to be cost-effective preventive degree to prevent dental caries. Saliva's fundamental constituent is water. In addition to that, there are few chemicals and microscopic organisms which help in oral health status support. It is a well-known fact that the low salivary $\mathrm{pH}$ would result in higher rate of caries. The higher $\mathrm{pH}$ will alter the ordinary microflora, which in turn will change the mouth balance influencing the periodontium antagonistically. Singh et al., [18] studied reinforce rinsing with plain water may be a good preventive step to be consolidated in preventive, promotive programs pointed at decreasing dental caries and gingivitis. Panchal and Gurunathan, [25] found that water flushing increments salivary $\mathrm{pH}$ after the diminishment with $50 \%$ sucrose solution. This in a roundabout way improves the caries anticipation and a straight forward mouth cleanliness hone which can be effectively used. In Tolentino et al, [26] study the volunteers flushed with refined water, and they found there was an increment in salivary $\mathrm{pH}$ amid the estimations. It can be clarified since of the increment within the saliva's bicarbonate concentration when salivary stream is increased, a condition that's common over time: salivary $\mathrm{pH}$ increments with the increment of stream.

Panchal and Gurunathan, [25] expressed that the clearance rate and the amount of salivary secretion alter the $\mathrm{pH}$. Also, in their study, the protective impact of tap water flush can be ascribed to increments in the clearance rate, treatment changing the $\mathrm{pH}$ having a more protective effect toward caries anticipation. Hence, modifying salivary buffering capacity by changing salivary $\mathrm{pH}$ can help as a preventive degree in dental caries. Mouth flushing with water having a more alkaline $\mathrm{pH}$ leads to extend in salivary $\mathrm{pH}$, which in this manner aids as a halt within the handle of demineralization by acidic corrosive generation.

\section{Comparison between} mouthwashes

As these mouthwashes have different $\mathrm{pH}$ and different in persisting time in the mouth, herbal mouthwash enhances salivary buffering capacity and show the highest salivary $\mathrm{pH}$ in compare with baseline salivary $\mathrm{pH}$ and other tested groups as it has highest $\mathrm{pH}$ (7.2) and persisted for longer period in the mouth (long durability), chlorohexidine in second place showed result approach to herbal mouthwash, homemade green tea mouthwash increases salivary $\mathrm{pH}$ after gargling but not reach baseline $\mathrm{pH}$ then $\mathrm{pH}$ decrease almost become acidic then increase gradually, green tea mouthwash show no enhancement for saliva buffering capacity, on the other hand tap water mouthwash increase salivary $\mathrm{pH}$ approach to baseline $\mathrm{pH}$ as it has an alkaline $\mathrm{pH}$, that persist for short period as it 
readily wash from the mouth, that mean enhance saliva buffering capacity for short period. Kalyani and Leelavathi, 2019 [14] concluded that chlorohexidine mouthwash had alkaline $\mathrm{pH}$, which is also drawn out in nature when compared to plain water, but we disagreed that chlorohexidine has higher and prolonger effect on salivary $\mathrm{pH}$ than herbal mouthwash as we use different herbal mouthwash. However, they have been measured salivary $\mathrm{pH}$ at 5 and 60 mints. The Kukreja and Dodwad, 2012 [27] declared that if people can utilize and advance such cost-effective measures (Herbal mouthwashes) of keeping up the oral health which are moreover destitute of any untoward side impacts, it may offer assistance in overcoming some common dental issues.

Bagchi et al., [6] owing to the side effects reported due to utilize of chlorhexidine mouth rinse and biocompatibility and well acknowledgment of herbal mouthwash by the consumer, it can be viably utilized as a replacing to chlorhexidine mouth rinse.

One of the limitations of the herbal mouthwashes that was reported by Abdullah et al., [1] study, as they found that herbal mouthwashes are corrosive to orthodontic appliance as the number of ions released from orthodontic appliance in herbal mouthwashes was higher than chlorohexidine mouthwash but didn't exceed the daily

recommended to be release from orthodontic appliance according to WHO. So prolonged use of these mouthwashes is not recommended. Dehghan et al., [28] found that mouth washing with chlorohexidine after an acidic challenge expanded salivary $\mathrm{pH}$. The chlorohexidine mouthwashes raised $\mathrm{pH}$ higher than water. Mouthwashes with a neutralizing impact can possibly decrease tooth disintegration from corrosive presentation. FLÖTRA et al., [29] instructed utilizing of chlorhexidine mouth washes for brief time only, due to their staining effects on the teeth. Vilela et al., [30] study supports the effectiveness of green tea mouthwash as an antibacterial option and as substitutes to chlorohexidine mouthwashes. However our results showed it failed to improve the salivary $\mathrm{pH}$ after extended period of time. Kaur et al., [31] study out comes showed that green tea catechin mouthwash contains a comparable antiplaque viability to chlorhexidine when utilized in a period of 7 days. Moreover, green tea catechin mouthwash due to its superior taste and no known sideeffects can be utilized on an everyday premise as an elective for chlorhexidine gluconate as an anti-plaque operator. It ought to be investigated as a long-term antiplaque flush with prophylactic benefits.

\section{Conclusion}

Herbal mouthwash is the best one to improve salivary $\mathrm{pH}$ and for longer duration after acidic challenger. Chlorohexidine mouthwash shows beneficial effects in elevation salivary $\mathrm{pH}$ higher than baseline $\mathrm{pH}$ and fast return to higher $\mathrm{pH}$ of saliva after acidic challenge. While Green tea mouthwash showed limited effects in elevation salivary $\mathrm{pH}$ after acidic challenge for long duration.

\section{Conflicts of interest}

The authors declare no competing interest.

\section{Acknowledgments}

We thank the Collage of Dentistry University of Mosul, Iraq on their support in conducting this research.

\section{References}

1. In-Vitro Evaluating the Effect of Different Mouthwashes on the lons Released from Orthodontic Bondable Molar Tubes. In-Vitro Abdullah, N. A., Hassan, F. A., and Nahidh, M. 2020; 25(02), 645- 654 . 
2. The salivary factors and dental erosion Romila, L., Sachelarie, L., Burlui, A., Vasiliu, M., and Farcas, D. M. International Journal of Medical Dentistry.2020; 24(1), 23-27.

3. ) Effect of Various Sugary Beverages on Salivary $\mathrm{pH}$, Flow Rate, and Oral Clearance Rate amongst Adults. Hans R, Thomas $S$, Garla B, Dagli R J. and Hans M K. Hindawi Publishing Corporation, Scientifica 2006; 10(2), 6.

4. Evaluation of Antibacterial Effect of Propolis and its Application in Mouthwash Production Nazeri, R., Ghaiour, M. and Abbasi, S. Frontiers in Dentistry. 2019; 16(1), 1.

5. Effects of Chlorhexidine mouthwash on the oral microbiome. Bescos, R., Ashworth, A., Cutler, C., Brookes, Z. L., Belfield, L., Rodiles, A. and White, D. Scientific Reports.2020; 10(1), 18.

6. Evaluation of efficacy of a commercially available* herbal mouthwash on dental plaque and gingivitis: A double-blinded parallel randomized controlled trial. Bagchi S, Saha S, Jagannath G V, Reddy V $K$, Sinha P. Journal Indian Association Public Health Dentistry. 2015; 13(3), 222-227.

7. Correlation between parotid saliva composition and dental caries using 31P-NMR and ICDAS score. Rovera, A., Rovera, G., Alzahrani, A., Hector, M., and Anderson, P. Archives of Oral Biology. 2020; 111(1), 104651.
8. Effect of saliva pH on shear bond strength of orthodontic brackets. Toodehzaeim, M. H. and Khanpayeh, E. Journal of dentistry (Tehran, Iran). 2015; 12(4), 257.

9. Comparative proteomic analysis on acquired enamel pellicle at two time points in cariessusceptible and caries-free subjects. Luo, J., Wang, Y., Wang, K., Jiang, W., Li, X., and Zhang, L. Journal of Dentistry, 2020; 94(10), 3301.

10. Dental erosion in mice with impaired salivary gland function.Tulek, A., Mulic, A., Refsholt Stenhagen, K., Galtung, H. K., Saeed, M., Utheim, T. P., and Sehic, A.). Acta Odonatological Scandinavica. 2020; 78(50), 1-11.

11. Are Vitamin Beverages Good for Dental Health?. Kang, A. R., Park, S. H., Woo, J. W., Hong, D. J., Kim, K. R., Sung, C. Y, and Jung, E. HJournal of dental hygiene science . 2020; 20(1), 9-15.

12. Comparative evaluation of antimicrobial properties of pomegranate peel extract against Streptococcus mutans and lactobacillus-an in vitro study. Kunte, S., Kadam, N., Patel, A., Shah, P., Lodaya, R., and Lakde, L. International Dental and Medical Journal of Advanced Research 2018; 4(1), 1-6.

13. Herbal product as mouthwash-a review. Sandhya, R. International Journal of Sciences and Researches. 2017; 6(7), 1334.

14. Comparison between the effect of plain water, herbal mouthwash, and chlorhexidine mouthwash on salivary $\mathrm{pH}$. Kalyani, P., and Leelavathi, L. Drug Invention Today. 2019; 11(5), 1184-1187.

15. Effects of Chlorhexidine mouthwash on the oral microbiome. Bescos, R., Ashworth, A., Cutler, C., Brookes, Z. L., Belfield, L., Rodiles, A., and White, D. Scientific Reports. 2020; 10(1), 1-8.

16. An in vivo comparison of plaque $\mathrm{pH}$ changes in children aged 8-12 years after consumption of milk and green tea with sugar.Talreja, N., Devendrappa, S. N., Singla, S. S., Agrawal, N., and Mali, S. Journal of International Oral Health. 2018; 10(1), 10.

17. Delivery of tea polyphenols to the oral cavity by green tea leaves and black tea extract. Lee, M. J., Lambert, J. D., Prabhu, S., Meng, X., Lu, H., Maliakal, P. and Yang, C. S. Cancer Epidemiology and Prevention Biomarkers. 2004; 13(1), 132-137.

18. Effectiveness of Green Tea Mouth Rinse over Combination Mouth Rinse in Restoring Salivary $\mathrm{pH}$ Post Sugar Exposure in Children. Singh, N. Journal of Scientific Research. (2020); 64(1), 20.

19. Efficacy of probiotic and green tea mouth rinse on salivary pH. Kamalaksharappa, S.K., Rai, R., Babaji, P., and Pradeep, M.C. Journal of Indian Society of Pedodontics and Preventive Dentistry. 2018; 36(2), 279-82. 
20. Effect of two different commercially available tea products on salivary $\mathrm{pH}: \mathrm{A}$ randomized double blinded concurrent parallel study. Srinidhi, P.B., Basha, S., Naveen Kumar, P., Prashant, G.M., Sushanth, V.H., and Imranulla, M. Dentistry and Medical Research. 2014; 2(39), 42.

21. Green tea effects on salivary $\mathrm{pH}$ and Streptococcus Mutans count. Rathod, V. C., Pundir, S., Dixit, S., Chandraker, N. K., and Desai, V. International Journal of innovation researches in dental scinces. 2017; 2(6), 4.

22. Effect of Green Tea on Salivary $\mathrm{Ph}$ and Streptococcus Mutans Count in Healthy Individuals. Sangameshwar, M., Vanishree, M., Surekha, R., Santosh, H., Anila, K., and Vardendra, M. International Journal of Oral and Maxillofacial Pathology. 2014; 5(1), 13-16.

23. The Effects of mouthwash on lactoperoxidase and $\mathrm{pH}$ in human saliva: Helpful or harmful. Lim, O. Journal of Future Science Leaders. 2014; 9(7), 6.

24. Comparison of Salivary $\mathrm{pH}$ Changes of Young Adults with Mineral and Alkaline Water Rinse After acidic challenge. A Clinical Study. Mosallam, R. S., \& Mohamed, M. S. Egyptian Dental Journal. 2019; 65(3-July (Fixed Prosthodontics, Dental Materials, Conservative Dentistry \& Endodontics)), 2511-2516.

25. Comparison of Salivary PH Changes with Tap Water and Mineral Water Rinse after 50\%
Sucrose Solution Rinse: A CrossOver Trial. Panchal, V., and Gurunathan, D. Journal Clinical Diagnosis Researches (2017); 6(140), 2376-0311.

26. Saliva and tongue coating $\mathrm{pH}$ before and after use of mouthwashes and relationship with parameters of halitosis. Tolentino, E. D. S., Chinellato, L. E. M., \& Tarzia, O. Journal of Applied Oral Science. 2011; 19(2), 90-94.

27. Herbal mouthwashes-a gift of nature. Kukreja, B. J., and Dodwad, V. International Journal of Pharmaceutical and Biological Sciences; 2012; 3(2), 46-52.

28. Neutralizing salivary $\mathrm{pH}$ by mouthwashes after an acidic challenge. Dehghan, M., Tantbirojn, D., Kymer-Davis, E., Stewart, C. W., Zhang, Y. H., Versluis, A., and Garcia-Godoy, F. Journal of investigative and clinical dentistry. 2017; 8(2) e12198.

29. Side effects of chlorhexidine mouth washes. FLÖTRA, L., Gjermo, P. E. R., RÖLLA, G., and WAERHAUG, J. European Journal of Oral Sciences. 1971; 79(2), 119-125.

30. Efficacy of green tea and its extract, epigallocatechin-3-gallate, in the reduction of cariogenic microbiota in children: a randomized clinical trial. Vilela, M. M., de Souza Salvador, S. L., Teixeira, I. G. L., Del Arco, M. C. G., and De Rossi, A. Archives of Oral Biology. 2020; 114(1), 104727.
31. Comparative evaluation of the antiplaque effectiveness of green tea catechin mouthwash with chlorhexidine gluconate. Kaur, H., Jain, S., and Kaur, AJournal of Indian Society of Periodontology. 2014; 18(2), 178. 